\title{
O desenho institucional dos conselhos nas cidades brasileiras de pequeno e médio porte: gestão de políticas públicas no poder local'
}

Eduardo Moreira da Silva

Universidade Federal de Minas Gerais (UFMG)

\begin{abstract}
O artigo compara os conselhos de políticas públicas em cidades brasileiras de médio e pequeno porte. O objetivo é identificar características do desenho institucional e o possível impacto da escala (porte do município) na dinâmica de funcionamento das referidas instituições. Pretende-se, ainda, oferecer subsídios para a compreensão da administração pública em municípios de pequeno porte. $O$ estudo foi desenvolvido por meio da construção de uma amostra com 59 municípios de pequeno e médio porte das cinco regiões brasileiras. Buscou-se testar a hipótese de que o porte do município incide sobre a configuração dos desenhos institucionais dos conselhos, sendo estes mais precários nas cidades menores. Procurou-se, ainda, verificar se o tipo de política pública (área temática) interfere na conformação do desenho institucional. Os resultados indicam a maior relevância do porte do município para explicar a incidência de desenho institucional mais precário em cidades pequenas. O tipo de política pública, por outro lado, não interfere na variação do desenho institucional dos conselhos pesquisados.
\end{abstract}

Palavras-chave: políticas públicas, administração municipal, democracia, participação social, conselho de administração, governança, institucionalização

\footnotetext{
${ }^{1}$ Agradeço aos pareceristas anônimos da revista pelas críticas e sugestões ao artigo.
}

[Artigo recebido em 30 de novembro de 2016. Aprovado em 4 de outubro de 2017.] 
El diseño institucional de los consejos en las ciudades brasileñas de pequeño y mediano porte: gestión de políticas públicas en el poder local

En este artículo se comparan los consejos de políticas públicas en ciudades brasileñas de medio y pequeño porte. El objetivo es identificar las características del diseño institucional y el posible impacto de la escala (tamaño del municipio) en la dinámica de funcionamiento de dichas instituciones. Se pretende también ofrecer subsidios para la comprensión de la administración pública en los municipios de pequeño porte. El estudio fue desarrollado a través de la construcción de una muestra de 59 municipios de porte pequeño y mediano de las cinco regiones brasileñas. Hemos tratado de probar la hipótesis de que el tamaño del municipio incide en la configuración de los diseños institucionales de los consejos, que son más precarios en las ciudades más pequeñas. Se intentó, incluso, comprobar si el tipo de política pública interfiere en la configuración del diseño institucional. Los resultados indican la mayor relevancia del porte del municipio para explicar la incidencia de diseño institucional más precario en ciudades pequeñas. El tipo de política pública, por otro lado, no interfiere en la variación del diseño institucional de los consejos investigados.

Palabras clave: políticas públicas, administración municipal, democracia, participación social, consejo de administración, gobernanza, institucionalización

\section{The institutional design of councils in Brazilian cities of small and medium size: management of policies in local power}

The paper compares policy councils of medium and small-sized Brazilian cities. Its goal is to identify characteristics of the institutional design and the possible impact of the municipal size on the dynamics of these institutions. It is also intended to offer subsidies for the understanding of public administration in small municipalities. The study was based on a sample with 59 towns from the five Brazilian regions. It tested the hypothesis that the size of the municipality affects the institutional designs of the councils, which are supposedly more precarious in smaller cities. It was also sought to verify if the type of public policy (policy area) interferes in the shaping of the institutional design. The results indicate the importance of the size of the municipality to explain the incidence of more precarious institutional design in small cities. The type of policies, on the other hand, does not interfere in the variation of the institutional design.

Keywords: public policies, municipal administration, democracy, social participation, board of directors, governance, institutionalization 


\section{Introdução}

A literatura acerca da participação política destaca como variável relevante para seu estudo a extensão territorial (escala) dos locais nos quais ela se desenvolve (MACPherson, 1978; PATEMAN, 1992; PARKInson, 2006; Silva et al., 2016). O novo pacto federativo derivado da Constituição Federal Brasileira de 1988 propiciou a emergência de um conjunto variado de arranjos institucionais que viabilizam a comunicação mais frequente dos cidadãos com o Estado. Tal situação é propiciada pelas instituições participativas (IPs), que podem ser agrupadas em três tipos básicos: i) as conferências de políticas públicas realizadas nos três níveis de governo; ii) os orçamentos participativos; e iii) os conselhos de políticas e de direitos ${ }^{2}$.

Quando observadas a partir do potencial que possuem para aproximar o Estado e a sociedade, os governantes e os governados, sobretudo nos interstícios eleitorais, tais instituições podem ser vistas como instrumentos importantes de influência dos cidadãos nas políticas públicas. Previstas por legislações constitucionais e ordinárias, em áreas cruciais como a saúde, assistência social e os direitos da criança e adolescente, tais instituições se disseminaram pelos diversos municípios brasileiros, a partir da década de 1990 (AVRITZER, 2016; LAVALLE, 2015).

As instituições participativas (doravante IPs) possuem quatro características principais, a saber: a) operam simultaneamente por meio dos princípios da participação e da representação; b) transformam as características voluntárias da sociedade civil em formas permanentes de organização política; c) interagem com partidos políticos e atores estatais; e, por fim, d) têm no desenho institucional um fator relevante para a sua efetividade (AVRITZER, 2009, p. 8). O último item será objeto de atenção mais detida.

A capacidade das IPs realmente propiciarem um canal permanente de comunicação entre Estado e sociedade, no entanto, depende de um conjunto de variáveis capazes de assegurar a inclusão política dos cidadãos no interior dessas instituições. Nesse sentido, uma agenda importante de pesquisa que tem se afirmado refere-se às investigações acerca das relações entre a qualidade da democracia e as instituições participativas (AVRITZER, 2011, p. 15). A esse respeito, ganham destaque as pesquisas relativas ao potencial inclusivo e democratizante identificável no desenho institucional'3; a discussão acerca da efetividade da deliberação ${ }^{4}$ desempenhada no interior desses espaços; a análise de sua capacidade de interlocução com outras arenas deliberativas (SILVA; RIBEIRO, 2016).

\footnotetext{
2 Há outras instituições participativas no Brasil (AVRITZER, 2009; PIRES; VAZ, 2014; CôRTEZ, 2011; WAMPLER, 2015). Centramos nas três por estarem mais amplamente disseminadas no poder local.

${ }^{3}$ Ver: Faria (2007); Faria e Coelho (2010, 2011); Silva (2010).

${ }^{4}$ Ver: Cunha (2009a, 2009b); Cunha e Rezende (2011).
} 
O foco do presente artigo é o desenho institucional dos conselhos de políticas públicas. Parte-se do pressuposto de que ele não é neutro, ou seja, tanto pode favorecer quanto dificultar a inclusão nesses espaços (FARIA; COELHO, 2011; CUNHA; THEOdoro, 2015). Para analisá-lo, partiremos de um conjunto de indicadores passíveis de serem aferidos empiricamente nas leis de criação e regimentos internos dos conselhos de saúde, de assistência social e dos direitos da criança e adolescente. Serão comparados os municípios de pequeno (até 20 mil habitantes) e médio porte (mais de 100 mil habitantes).

O artigo está estruturado em três partes. A primeira analisa o grau de institucionalização desses conselhos, a partir dos seguintes elementos: "i) tempo de existência dessas instituições; ii) a existência de uma estrutura organizacional; iii) a freqüência de reuniões obrigatórias" (FARIA; COELHO, 2011, p. 128). A segunda parte aborda o potencial inclusivo e o grau de democratização dos conselhos, por meio de uma descrição analítica dos seguintes elementos: i) composição, pluralidade e proporcionalidade entre os segmentos; ii) processo decisório; iii) presença de comissões; iv) previsão de conferências (FARIA; COELHO, 2011, p. 128-9). Por fim, a terceira parte descreve e analisa o grau de representação nos conselhos, a partir da análise das seguintes informações: “i) definição das entidades que têm assento nessas instituições; ii) o número de cadeiras destinadas a cada segmento; e iii) as formas pelas quais estas definições ocorrem" (FARIA; COELHO, 2011, p. 130). Nas considerações finais são apresentadas as principais conclusões e indica-se a agenda de pesquisa a ser explorada no campo.

\section{Governança democrática e o grau de institucionalização das IPs: características do desenho institucional dos conselhos dos municípios de médio e pequeno porte}

Apesar de existir um número expressivo de pesquisas sobre os conselhos de políticas públicas, no Brasil, há uma lacuna acerca dos municípios de pequeno porte em perspectiva comparativa ${ }^{5}$. As primeiras pesquisas realizaram estudos de caso de municípios diversos (TATAGIBA, 2002; SILVA, 2010). Seguiram-se estudos comparativos, incluindo pesquisas sobre as regiões metropolitanas das cinco regiões brasileiras (SANTOS JúNIOR; AZEVEDO; RIBEIRO, 2004). Outros estudos mostraram a dinâmica dessas instituições em capitais importantes do país e, também, em municípios com mais de 100.000 habitantes (AVRITZER, 2007a, 2010;

\footnotetext{
${ }^{5}$ A pesquisa A dinâmica da participação local no Brasil, financiada pela Fundação do Amparo à Pesquisa do Estado de Minas Gerais (Fapemig) e coordenada pelo Prof. Leonardo Avritzer, cujos dados são apresentados adiante, cumpre a função de investigar os aspectos característicos dos conselhos de municípios com população de até 20.000 habitantes localizados em Minas Gerais. Agradecemos ao coordenador por ter disponibilizado os dados da pesquisa.
} 
FUKS; PERISSINOTO, 2006). A partir do início dos anos 2000, a literatura passou a pesquisar a representatividade dos conselhos que compõem essas instituições (AVritzer, 2007a; LaValle; Houtzager; CAStelo, 2006a, 2006b; Lüchman, 2007). Recentemente, o desafio tem sido investigar a interação desses espaços com outras arenas deliberativas do sistema político (ALMEIDA; CUNHA, 2016; MENDONÇA, 2016; Silva; RibeIRo, 2016). Permanece, no entanto, uma lacuna sobre a dinâmica dos conselhos em cidades com menos de 20.000 habitantes, apesar de representarem mais de $70 \%$ das cidades brasileiras.

É importante se analisar o grau de institucionalização dos conselhos no poder local. Além de analisar se há diferença entre os conselhos quando se passa das cidades de médio para pequeno porte, é relevante verificar se o tipo de política pública se apresenta como uma variável explicativa relevante (LÜCHMAN, 2007). Nesse sentido, os conselhos serão analisados em perspectiva comparada, em três áreas: saúde, assistência social e direitos da criança e adolescente.

Tabela 1 - Número de conselhos pesquisados por cidade de médio e pequeno porte $^{6}$

\begin{tabular}{|c|c|c|c|c|c|c|c|c|c|}
\hline \multirow{2}{*}{$\begin{array}{l}\text { Cidades de } \\
\text { porte médio }\end{array}$} & \multicolumn{3}{|c|}{ Conselhos } & \multirow{2}{*}{ Total } & \multirow{2}{*}{$\begin{array}{l}\text { Cidades de } \\
\text { pequeno } \\
\text { porte }\end{array}$} & \multicolumn{3}{|c|}{ Conselhos } & \multirow[t]{2}{*}{ Total } \\
\hline & CMS & CMAS & CMDCA & & & CMS & CMAS & CMDCA & \\
\hline Chapecó & 1 & 1 & 1 & 3 & Alpinópolis & 1 & 1 & 1 & 3 \\
\hline Juiz de Fora & 1 & 1 & 1 & 3 & Alvinópolis & 1 & 0 & 1 & 2 \\
\hline São Leopoldo & 0 & 1 & 1 & 2 & Arinos & 1 & 1 & 1 & 3 \\
\hline $\begin{array}{c}\text { Poços de } \\
\text { Caldas }\end{array}$ & 1 & 1 & 1 & 3 & Belo Oriente & 1 & 1 & 1 & 3 \\
\hline Petrópolis & 1 & 1 & 1 & 3 & $\begin{array}{c}\text { Bom Suces- } \\
\text { so }\end{array}$ & 1 & 1 & 1 & 3 \\
\hline $\begin{array}{c}\text { Volta Redon- } \\
\text { da }\end{array}$ & 1 & 1 & 1 & 3 & $\begin{array}{l}\text { Campina } \\
\text { Verde }\end{array}$ & 1 & 1 & 1 & 3 \\
\hline Anápolis & 1 & 1 & 1 & 3 & $\begin{array}{c}\text { Carmo do } \\
\text { Cajuru }\end{array}$ & 0 & 1 & 1 & 2 \\
\hline Cubatão & 1 & 1 & 1 & 3 & $\begin{array}{l}\text { Carmo do } \\
\text { Rio Claro }\end{array}$ & 1 & 1 & 1 & 3 \\
\hline $\begin{array}{l}\text { Águas Lindas } \\
\text { de Goiás }\end{array}$ & 1 & 1 & 1 & 3 & $\begin{array}{c}\text { Chapada do } \\
\text { Norte }\end{array}$ & 1 & 1 & 1 & 3 \\
\hline
\end{tabular}

\footnotetext{
6 Para simplificar exposição nas tabelas, relacionamos aqui a lista completa das cidades e os respectivos estados: Chapecó/SC, Juiz de Fora/MG, São Leopoldo/RS, Poços de Caldas/MG, Petrópolis/RJ, Volta Redonda/RJ, Anápolis/ GO, Cubatão/SP, Águas Lindas de Goiás/GO, Lages/SC, Alpinópolis/MG, Alvinópolis/MG, Arinos/MG, Belo Oriente/MG, Bom Sucesso/MG, Campina Verde/MG, Carmo do Cajuru/MG, Carmo do Rio Claro/MG, Chapada do Norte/MG, Conceição das Alagoas/MG, Monte Alegre de Minas/MG. Esclarecemos que o porte do município é aqui tratado como sinônimo de tamanho.
} 


\begin{tabular}{|c|c|c|c|c|c|c|c|c|c|}
\hline Lages & 1 & 1 & 1 & 3 & $\begin{array}{l}\text { Conceição } \\
\text { das Alagoas }\end{array}$ & 1 & 0 & 0 & 1 \\
\hline- & - & - & - & - & $\begin{array}{l}\text { Monte } \\
\text { Alegre de } \\
\text { Minas }\end{array}$ & 1 & 1 & 1 & 3 \\
\hline $\begin{array}{l}\text { Total Cidades } \\
\text { médias }\end{array}$ & 9 & 10 & 10 & 29 & $\begin{array}{l}\text { Total Ci- } \\
\text { dades } \\
\text { pequenas }\end{array}$ & 10 & 9 & 10 & 29 \\
\hline
\end{tabular}

A Tabela 1 apresenta o número total de conselhos pesquisados nas três áreas de políticas públicas. Não há grandes variações no número de conselhos em relação ao tamanho de cidade. Isso mostra que a legislação federal que condicionou o repasse de recursos à necessidade de que haja um conselho em funcionamento nos municípios foi exitosa e possibilitou a criação dessas instituições nos municípios de pequeno porte analisados.

No que concerne à área específica de política pública, não é possível observar variações significativas, pois os três conselhos estão presentes, praticamente, em todos os municípios de pequeno e médio porte. Portanto, no que diz respeito às políticas sociais básicas, é possível afirmar que a quase totalidade das cidades que compuseram a amostra da pesquisa ofertam os serviços dessas áreas à população, inclusive ao público infanto-juvenil, com a participação do Conselho Municipal dos Direitos da Criança e do Adolescente (CMDCA). Mais do que isso, é possível supor que o processo decisório das ações dessas três áreas de políticas seja realizado pelos respectivos conselhos. A Tabela 2, abaixo, indica a data de criação desses conselhos.

Tabela 2 - Ano de criação dos conselhos

\begin{tabular}{|c|c|c|c|c|c|c|c|c|c|c|}
\hline & \multirow{2}{*}{\multicolumn{2}{|c|}{ CMS }} & \multirow{2}{*}{\multicolumn{2}{|c|}{ CMAS }} & \multirow{2}{*}{\multicolumn{2}{|c|}{ CMDCA }} & \multicolumn{4}{|c|}{ Total } \\
\hline & & & & & & & \multicolumn{2}{|c|}{$\begin{array}{c}\text { Cidade } \\
\text { de médio } \\
\text { porte }\end{array}$} & \multicolumn{2}{|c|}{$\begin{array}{l}\text { Cidade de } \\
\text { pequeno } \\
\text { porte }\end{array}$} \\
\hline & $\begin{array}{l}\text { Cidade } \\
\text { de } \\
\text { médio } \\
\text { porte }\end{array}$ & \begin{tabular}{|c|}
$\begin{array}{c}\text { Cidade } \\
\text { de } \\
\text { pequeno } \\
\text { porte }\end{array}$ \\
\end{tabular} & \begin{tabular}{|c|} 
Cidade \\
de \\
médio \\
porte
\end{tabular} & $\begin{array}{c}\text { Cidade } \\
\text { de } \\
\text { pequeno } \\
\text { porte }\end{array}$ & $\begin{array}{l}\text { Cidade } \\
\text { de } \\
\text { médio } \\
\text { porte }\end{array}$ & $\begin{array}{c}\text { Cidade } \\
\text { de } \\
\text { pequeno } \\
\text { porte }\end{array}$ & $N$ & $\%$ & $N$ & $\%$ \\
\hline $\begin{array}{c}\text { De } 1988 \text { a } \\
1995\end{array}$ & 8 & 9 & 4 & 4 & 9 & 6 & 21 & 72,41 & 19 & 65,52 \\
\hline $\begin{array}{c}\text { De } 1996 \text { a } \\
2008\end{array}$ & 1 & 1 & 6 & 4 & 1 & 3 & 8 & 27,59 & 8 & 27,59 \\
\hline $\begin{array}{c}\text { Sem } \\
\text { informação }\end{array}$ & 0 & 0 & 0 & 1 & 0 & 1 & 0 & 0,00 & 2 & 6,90 \\
\hline TOTAL & 9 & 10 & 10 & 9 & 10 & 10 & 29 & 100,00 & 29 & 100,00 \\
\hline
\end{tabular}


Como se pode observar na Tabela $2,72,41 \%$ dos conselhos das cidades de médio porte e $65,52 \%$ dos conselhos nas cidades de pequeno porte foram criados entre 1988 e 1995. No período subsequente de 1996-2008, encontramos 27,59\% dos conselhos criados. Tais instituições possuem uma história já consolidada nos municípios pesquisados.

Em relação ao tipo de política pública, observa-se que os conselhos mais antigos são os da área da saúde, nos dois tipos de municípios, e os mais recentes são os conselhos de assistência social. Na posição intermediária, vem o CMDCA, mas nesse caso há uma pequena diferença em relação ao tamanho de cidade, pois a grande maioria dos conselhos possui mais de 22 anos de existência, ao passo que, nos municípios de pequeno porte, cerca de um terço deles está localizada no segundo intervalo temporal. Portanto, a redução no tamanho de cidade implica na criação mais tardia de alguns CMDCAs. Considerando-se a data de 1990, ano em que foi promulgado o ECA, com o início da obrigatoriedade dos CMDCAs, três municípios levaram pelo menos seis anos para criá-los.

Tabela 3 - Ano de criação do regimento interno (RI) em vigor

\begin{tabular}{|c|c|c|c|c|c|c|c|c|c|c|}
\hline & \multicolumn{6}{|c|}{ Número de conselhos por período de criação do RI } & \multicolumn{4}{|c|}{ Total } \\
\hline & \multicolumn{2}{|c|}{ CMS } & \multicolumn{2}{|c|}{ CMAS } & \multicolumn{2}{|c|}{ CMDCA } & \multicolumn{2}{|c|}{$\begin{array}{c}\text { Cidade } \\
\text { de médio } \\
\text { porte }\end{array}$} & \multicolumn{2}{|c|}{$\begin{array}{c}\text { Cidade de } \\
\text { pequeno } \\
\text { porte }\end{array}$} \\
\hline & $\begin{array}{l}\text { Cidade } \\
\text { de } \\
\text { médio } \\
\text { porte }\end{array}$ & $\begin{array}{c}\text { Cidade } \\
\text { de } \\
\text { pequeno } \\
\text { porte }\end{array}$ & $\begin{array}{c}\text { Cidade } \\
\text { de } \\
\text { médio } \\
\text { porte }\end{array}$ & $\begin{array}{c}\text { Cidade } \\
\text { de } \\
\text { pequeno } \\
\text { porte }\end{array}$ & $\begin{array}{l}\text { Cidade } \\
\text { de } \\
\text { médio } \\
\text { porte }\end{array}$ & $\begin{array}{c}\text { Cidade } \\
\text { de } \\
\text { pequeno } \\
\text { porte }\end{array}$ & $\mathbf{N}$ & $\%$ & $\mathbf{N}$ & $\%$ \\
\hline $\begin{array}{c}\text { De } 1988 \text { a } \\
1995\end{array}$ & 0 & 1 & 0 & 0 & 0 & 0 & 0 & 0,0 & 1 & 3,45 \\
\hline $\begin{array}{c}\text { De } 1996 \text { a } \\
2008\end{array}$ & 5 & 3 & 8 & 4 & 7 & 4 & 20 & 68,96 & 11 & 37,93 \\
\hline $\begin{array}{c}2009 \mathrm{em} \\
\text { diante }\end{array}$ & 0 & 3 & 0 & 3 & 0 & 4 & 0 & 0,0 & 10 & 34,48 \\
\hline $\begin{array}{c}\text { Sem } \\
\text { informação }\end{array}$ & 4 & 3 & 2 & 2 & 3 & 2 & 09 & 31,03 & 7 & 24,14 \\
\hline Total & 9 & 10 & 10 & 9 & 10 & 10 & 29 & 100,0 & 29 & 100,00 \\
\hline
\end{tabular}

Uma informação merece ser combinada com o ano de criação dos conselhos: o ano de criação dos regimentos internos dessas instituições, como se vê na Tabela 3. Esse é o documento que estabelece as regras de interação entre atores componentes da instituição, tais como os critérios de escolha dos conselheiros, as normas do processo deliberativo, quem e como se pode ocupar a presidência, quem elabora a pauta, como se dá o processo decisório etc. Nesse sentido, é um dos principais determinantes do desenho institucional, pois está relacionado ao 
modo como o poder é distribuído entre os atores. Em contraste com o ano de criação dos conselhos, os regimentos internos foram criados, em sua maioria, a partir de 1996. Há uma diferença no tempo de existência do RI, se compararmos por tamanho de cidade, pois a maioria das cidades de médio porte $(68,96 \%)$ criou os regimentos entre 1996 e 2008, ao passo que, nos municípios de pequeno porte, aproximadamente um terço dos conselhos têm RI datado do período de 1996 a 2008 e, o outro terço, a partir de 2009. Nessa última condição situam-se os CMDCAs.

A criação e a possibilidade de alteração no regimento interno pode ser um indicativo de que os conselhos reveem constantemente as suas práticas, o que pode indicar uma possível maleabilidade e flexibilidade dos conselhos no processo de modelagem do desenho institucional. Esse dado pode sugerir também certa instabilidade institucional. Por outro lado, alguns analistas têm destacado que uma concentração de tempo muito grande na revisão das normas internas retira o foco de atuação da instituição nas questões mais relevantes, como a formulação e o controle da implementação das políticas (TATAGIBA, 2002; CUNHA, 2009a; SILVA, 2010). O tipo de política pública não é um elemento diferenciador dos conselhos, no que se refere ao ano de criação do RI.

A frequência das reuniões ordinárias dos conselhos é outro indicador do grau de institucionalização dos mesmos. Entende-se como indício do estabelecimento de uma rotina de funcionamento a realização de reuniões periódicas. Ao contrário, conselhos que não possuem uma periodicidade de reuniões seriam considerados pouco institucionalizados. A Tabela 4 nos mostra que cerca de $90 \%$ dos conselhos das cidades de médio porte realizam reuniões mensais. Essa mesma periodicidade é adotada por aproximad amente $80 \%$ dos conselhos das cidades de pequeno porte. Trata-se de uma frequência regular de reuniões, o que indica um bom sinal de consolidação dos encontros e deliberações entre os conselheiros.

Tabela 4 - Frequência das reuniões ordinárias

\begin{tabular}{c|c|c|c|c|c|c|c|c|c|c}
\hline & \multicolumn{8}{c}{ Número de conselhos por frequência de reunião } \\
\hline & \multicolumn{2}{|c|}{ CMS } & \multicolumn{2}{c}{ CMAS } & \multicolumn{2}{c}{ CMDCA } & \multicolumn{4}{c}{ Total } \\
\hline & $\begin{array}{c}\text { Cidade } \\
\text { de } \\
\text { médio } \\
\text { porte }\end{array}$ & $\begin{array}{c}\text { Cidade } \\
\text { de } \\
\text { pequeno } \\
\text { porte }\end{array}$ & $\begin{array}{c}\text { Cidade } \\
\text { de } \\
\text { médio } \\
\text { porte }\end{array}$ & $\begin{array}{c}\text { Cidade } \\
\text { de } \\
\text { pequeno } \\
\text { porte }\end{array}$ & $\begin{array}{c}\text { Cidade } \\
\text { de } \\
\text { médio } \\
\text { porte }\end{array}$ & $\begin{array}{c}\text { Cidade } \\
\text { de } \\
\text { pequeno } \\
\text { porte }\end{array}$ & $\begin{array}{c}\text { Cidade } \\
\text { de médio } \\
\text { porte }\end{array}$ & $\begin{array}{c}\text { Cidade de } \\
\text { pequeno } \\
\text { porte }\end{array}$ \\
\hline Mensal & 9 & $\mathbf{N}$ & $\mathbf{N}$ & $\mathbf{N}$ & $\mathbf{N}$ & $\mathbf{N}$ & $\mathbf{N}$ & $\%$ & $\mathbf{N}$ & $\%$ \\
\hline Quinzenal & 0 & 0 & 0 & 0 & 2 & 0 & 2 & 6,90 & 0 & 0,00 \\
\hline $\begin{array}{c}\text { Sem } \\
\text { informação }\end{array}$ & 0 & 3 & 0 & 2 & 2 & 1 & 2 & 6,90 & 6 & 20,69 \\
\hline Total & $\mathbf{9}$ & $\mathbf{1 0}$ & $\mathbf{1 0}$ & $\mathbf{9}$ & $\mathbf{1 0}$ & $\mathbf{1 0}$ & $\mathbf{2 9}$ & $\mathbf{1 0 0 , 0 0}$ & $\mathbf{2 9}$ & $\mathbf{1 0 0 , 0 0}$ \\
\hline Fonte: AVRITZER et al, 2013. & & & & & & & 26 & 89,66 & 23 & 79,31 \\
\hline
\end{tabular}


A existência dos conselhos das três áreas de políticas, na quase totalidade dos municípios pesquisados, com um longo tempo de existência, coloca ainda em suspenso as seguintes perguntas: Há diferenças significativas na estrutura organizacional desses conselhos? Se houver, o tamanho do município pode explicar tais diferenças? O tipo de política pública é uma variável capaz de diferenciar tais conselhos?

Vejamos quais são as características desses conselhos no que se refere à estrutura organizacional de cada um deles. Ao analisar o desenho institucional dos CMDCAs de oito capitais brasileiras, Menicucci (2010) indicou que eles possuem: mesa diretora, secretaria executiva e comissões. Não se diferenciam, portanto, em relação a esse quesito. Isso leva a autora a sustentar a existência de certo mimetismo organizacional, apontado, inclusive, por outras pesquisas sobre o assunto.

A presença dessas estruturas organizacionais pode ser tomada como um indicativo da institucionalização de práticas e rotinas administrativas no interior dos conselhos. A existência de mesa diretora, secretaria executiva e o plenário indica uma especialização da dinâmica de funcionamento dos conselhos. As comissões temáticas, por sua vez, aprimoram e qualificam os debates realizados entre os conselheiros (FARIA, 2007; FARIA; COELHO, 2011).

Os municípios de médio porte se assemelham bastante àqueles das capitais. Mas nas cidades de pequeno porte, os conselhos, na sua totalidade, não possuem a mesma estrutura organizacional. Curiosamente, todos os dez conselhos possuem câmaras ou comissões temáticas, indicando um possível refinamento do processo de discussão entre os conselheiros, a despeito da ausência de demais estruturas que são até mais facilmente presentes nos conselhos. Quando passamos à análise dos municípios de pequeno porte, a ausência dessas estruturas organizacionais é bem mais expressiva. Portanto, a redução da escala, na análise dos dados dos CMDCAs das capitais aos municípios de pequeno porte, implica em uma diminuição da presença dessas estruturas organizacionais. A ausência das mesmas se acentua na passagem dos municípios de médio para pequeno porte, como nos mostram os dados agregados para os três conselhos na parte direta da Tabela 5.

Quando introduzimos a variável tipo de política pública, é possível observar uma pequena diferença entre as três áreas. Embora se mantenha a tendência geral de decréscimo na presença das estruturas quando passamos das cidades de médio para aquelas de pequeno porte, a área da saúde é a que apresenta o maior número de municípios de pequeno porte que não possuem as referidas estruturas organizacionais. Trata-se de uma situação atípica, na medida em que essa área de política pública, entre as três, é a que possui a trajetória participativa mais antiga, o que tende a se refletir na melhor estrutura dos conselhos da área. 
Tabela 5 - Estrutura organizacional dos conselhos

\begin{tabular}{|c|c|c|c|c|c|c|c|c|c|c|}
\hline & \multicolumn{6}{|c|}{ Número de estruturas organizacionais por conselho } & \multicolumn{4}{|c|}{ Total } \\
\hline & \multicolumn{2}{|c|}{ CMS } & \multicolumn{2}{|c|}{ CMAS } & \multicolumn{2}{|c|}{ CMDCA } & \multicolumn{2}{|c|}{$\begin{array}{l}\text { Cidades de } \\
\text { médio porte }\end{array}$} & \multicolumn{2}{|c|}{$\begin{array}{c}\text { Cidades de } \\
\text { pequeno } \\
\text { porte }\end{array}$} \\
\hline & $\begin{array}{c}\text { Cidades } \\
\text { de } \\
\text { médio } \\
\text { porte }\end{array}$ & $\begin{array}{c}\text { Cidades } \\
\text { de } \\
\text { pequeno } \\
\text { porte }\end{array}$ & $\begin{array}{l}\text { Cidades } \\
\text { de } \\
\text { médio } \\
\text { porte }\end{array}$ & $\begin{array}{c}\text { Cidades } \\
\text { de } \\
\text { pequeno } \\
\text { porte }\end{array}$ & $\begin{array}{c}\text { Cidades } \\
\text { de } \\
\text { médio } \\
\text { porte }\end{array}$ & $\begin{array}{c}\text { Cidades } \\
\text { de } \\
\text { pequeno } \\
\text { porte }\end{array}$ & $\mathbf{N}$ & $\%$ & $\mathbf{N}$ & $\%$ \\
\hline $\begin{array}{c}\text { Mesa } \\
\text { Diretora }\end{array}$ & 6 & 4 & 9 & 5 & 9 & 7 & 24 & 15,29 & 16 & 22,54 \\
\hline Plenário & 7 & 6 & 9 & 7 & 9 & 8 & 38 & 24,20 & 23 & 32,39 \\
\hline $\begin{array}{l}\text { Secretaria } \\
\text { Executiva }\end{array}$ & 9 & 3 & 8 & 6 & 9 & 4 & 35 & 22,29 & 13 & 18,31 \\
\hline $\begin{array}{c}\text { Câmaras ou } \\
\text { comissões } \\
\text { temáticas }\end{array}$ & 7 & 2 & 8 & 6 & 10 & 4 & 33 & 21,02 & 12 & 16,90 \\
\hline $\begin{array}{c}\text { Conferência } \\
\text { municipal }\end{array}$ & 9 & 2 & 8 & 3 & 5 & 2 & 27 & 17,20 & 7 & 9,86 \\
\hline Total & 38 & 17 & 42 & 27 & 42 & 25 & 157 & 100,00 & 71 & 100,00 \\
\hline
\end{tabular}

Fonte: AVRItZER et al, 2013.

Outro indicador do grau de institucionalização das políticas participativas nos municípios é a capacidade de realizar conferências. Estas são, em geral, organizadas pelos conselhos das respectivas áreas de políticas públicas. Sua realização periódica pode ser vista como indicativo do grau de institucionalização dos conselhos. Destaca-se uma redução muito expressiva do número de municípios que realizam conferências, passando de 93,10\% (27 em 29) das cidades de médio porte para apenas $24,14 \%$ (7 em 29) nas de pequeno porte.

Se observarmos os dados a partir do tipo de política pública, a área da criança e do adolescente é a que menos realiza as conferências, nos dois tipos de municípios. Como as conferências expressam a capacidade de ampliar o público que participa e propõem ações para serem adotadas no âmbito das políticas públicas, o indicativo de sua existência mostra a capacidade dos conselhos de cumprir a legislação e uma maior abertura e porosidade dessas instituições à sociedade.

A maior parte dos conselhos foi criada entre os anos de 1988 e 1995, indicando que possuem pelos menos duas décadas de existência. Pode ser um indício da existência de práticas e procedimentos rotineiros desenvolvidos em prol das políticas. A data de promulgação das leis que regulamentaram a obrigatoriedade da existência dessas instituições nos municípios brasileiros como condição necessária para o recebimento de repasses do Governo Federal nas respectivas áreas de políticas pode ser a explicação. Trata-se da Lei Orgânica da Saúde (LOS) e do Estatuto 
da Criança e do Adolescente (ECA), ambos promulgados em 1990, e da Lei Orgânica da Assistência Social (LOAS) de 19937.

No que se refere ao tipo de política pública, não há diferenças muito significativas entre os conselhos das três áreas analisadas. Apenas no quesito estrutura organizacional observou-se uma presença um pouco inferior de mesa diretora, plenário e secretaria executiva, nos conselhos de saúde.

A variável tamanho de cidade apresenta um grau mais expressivo de explicação na diferenciação entre os conselhos, principalmente no que se refere ao ano de criação do RI e nos itens componentes da estrutura organizacional. Nesse sentido, a redução no tamanho da cidade implica na criação mais tardia do RI e, ainda, na redução da presença dos cinco itens que compõem a estrutura organizacional. Em outros termos, os municípios menores tendem a ter regimentos internos criados mais recentemente e que não preveem a estrutura organizacional geralmente presente nos conselhos de cidades maiores. No próximo tópico são analisadas as características do desenho institucional relativas às condições para o desenvolvimento do processo deliberativo no interior dos conselhos.

\section{O desenho institucional e as condições para a deliberação}

A literatura pertinente tem desenvolvido uma série de estudos no intuito de investigar como os conselheiros têm desenvolvido os processos deliberativos precedentes às decisões produzidas pelos conselhos (AVRITZER, 2010; CUNHA, 2009a, 2009b; CUNHA, 2015). Uma técnica de análise tem se destacado a esse respeito, qual seja, a análise de atas. Parte-se do princípio de que esses documentos cumprem a função de registrar as dinâmicas ocorridas durante as reuniões dos conselhos e de que todos os conselheiros devem aprovar o documento que foi redigido antes que ele seja disponibilizado ao público. Nesse sentido, os documentos contam com anuência daqueles que tiveram suas falas registradas e transpostas para a ata. Busca-se, assim, aferir a efetividade deliberativa ${ }^{8}$ dos conselhos.

A perspectiva adotada aqui é diferente, pois o objetivo é observar uma etapa anterior do processo, mas extremamente importante e determinante do modo como a deliberação irá se desenvolver. Trata-se das regras presentes no desenho

\footnotetext{
${ }^{7}$ Lavalle, Voigt e Serafim (2016) analisaram os diários oficiais dos municípios e concluiram que o tempo de criação das instituições não corresponde exatamente à data de promulgação da legislação que as tornaram obrigatórias. Isto é, há uma distância entre a legislação e a criação institucional, particularmente na área da criança e do adolescente, na qual a maior parte dos conselhos é criada a partir de 1996.

${ }^{8}$ O conceito foi formulado por Cunha (2010, p. 98) e é assim definido por ela: "a capacidade efetiva dessas instituições influenciarem, controlarem e decidirem sobre determinada política pública, expressa na institucionalização dos procedimentos, na pluralidade da composição, na deliberação pública e inclusiva, na proposição de novos temas, na decisão sobre as ações públicas e no controle dessas ações".
} 
institucional, que podem facilitar ou constranger a interação que irá se estabelecer entre os participantes. Nesse sentido, seguimos a sugestão de Faria e Coelho (2011) para analisar o potencial inclusivo e democratizante dos conselhos. Para tanto, buscamos aferir os seguintes elementos: i) a composição, a pluralidade e a proporcionalidade; ii) as regras do processo decisório; iii) a presença de comissões; iv) a previsão de conferências.

A questão da composição apresenta dois aspectos importantes, quais sejam: a distribuição e a proporcionalidade das cadeiras ocupadas pelos segmentos do governo e da sociedade civil. Os teóricos deliberativos abordam essa questão em função do potencial de conferir voz aos distintos segmentos envolvidos com a política pública e, possivelmente, aumentar o número de razões e opiniões apresentadas ao debate nos fóruns deliberativos (ALMEIDA; CUNHA, 2011). A resolução de um problema pode ser aperfeiçoada se forem consideradas as diferentes perspectivas e opiniões sobre o tema. Assim, é importante considerar quais são os segmentos que possuem assento no conselho e, ainda, a proporcionalidade entre eles, na medida em que a distribuição de cadeiras está diretamente relacionada à distribuição do poder entre os membros. Isto é, a existência de um equilíbrio entre os segmentos é salutar para que nenhum deles tenha a capacidade, sozinho, de aprovar as questões por ele defendidas. Nesse sentido, as decisões devem ser construídas com colaboração de todos os segmentos. Vejamos o que nos dizem os dados a partir da Tabela 6.

Tabela 6 - Composição dos conselhos

\begin{tabular}{|c|c|c|c|c|c|c|c|c|c|c|}
\hline & \multicolumn{6}{|c|}{ Número de conselhos por processo de votação } & \multicolumn{4}{|c|}{ Total } \\
\hline & \multicolumn{2}{|c|}{ CMS } & \multicolumn{2}{|c|}{ CMAS } & \multicolumn{2}{|c|}{ CMDCA } & \multicolumn{2}{|c|}{$\begin{array}{l}\text { Cidades } \\
\text { de médio } \\
\text { porte }\end{array}$} & \multicolumn{2}{|c|}{$\begin{array}{c}\text { Cidades de } \\
\text { pequeno } \\
\text { porte }\end{array}$} \\
\hline & $\begin{array}{c}\text { Cidades } \\
\text { de } \\
\text { médio } \\
\text { porte }\end{array}$ & $\begin{array}{c}\text { Cidades } \\
\text { de } \\
\text { pequeno } \\
\text { porte }\end{array}$ & $\begin{array}{c}\text { Cidades } \\
\text { de } \\
\text { médio } \\
\text { porte }\end{array}$ & $\begin{array}{c}\text { Cidades } \\
\text { de } \\
\text { pequeno } \\
\text { porte }\end{array}$ & $\begin{array}{c}\text { Cidades } \\
\text { de } \\
\text { médio } \\
\text { porte }\end{array}$ & $\begin{array}{c}\text { Cidades } \\
\text { de } \\
\text { pequeno } \\
\text { porte }\end{array}$ & N & $\%$ & $\mathbf{N}$ & $\%$ \\
\hline $\begin{array}{l}50 \% \mathrm{G} \mathrm{e} \\
50 \% \mathrm{SC}\end{array}$ & 0 & 1 & 9 & 7 & 10 & 9 & 19 & 65,52 & 17 & 58,62 \\
\hline $\begin{array}{l}50 \% \text { U } \\
\text { e } 50 \% \\
\text { divididos } \\
\text { entre T, P } \\
\text { e G }\end{array}$ & 7 & 8 & 0 & 0 & 0 & 0 & 7 & 24,14 & 8 & 27,59 \\
\hline $\begin{array}{l}50 \% \text { U } \\
\text { e } 50 \% \\
\text { dividido } \\
\text { entre T e G }\end{array}$ & 1 & 1 & 0 & 0 & 0 & 0 & 1 & 3,45 & 1 & 3,45 \\
\hline
\end{tabular}




\begin{tabular}{c|c|c|c|c|c|c|c|c|c|c}
\hline $\begin{array}{l}\text { Sem infor- } \\
\text { mação }\end{array}$ & 1 & 0 & 1 & 2 & 0 & 1 & 2 & 6,90 & 3 & 10,34 \\
\hline Total & $\mathbf{9}$ & $\mathbf{1 0}$ & $\mathbf{1 0}$ & $\mathbf{9}$ & $\mathbf{1 0}$ & $\mathbf{1 0}$ & $\mathbf{2 9}$ & $\mathbf{1 0 0 , 0 0}$ & $\mathbf{2 9}$ & $\mathbf{1 0 0 , 0 0}$ \\
\hline
\end{tabular}

Legenda: SC - sociedade civil; G - governo; T- trabalhador; P - prestador de serviço; U- usuário.

Fonte: AVRITZER et al, 2013.

Destaca-se a concentração de conselhos que distribuem paritariamente o número de cadeiras entre o governo e a sociedade civil. Temos 19 conselhos nessa situação nas cidades de médio porte, o que representa $65,52 \%$ do total de conselhos; e 17 conselhos nas cidades de pequeno porte, ou seja, 58,62\% do total. Os CMDCAs possuem esse tipo de distribuição na totalidade dos municípios de pequeno porte e na quase totalidade ( 9 em 10) dos municípios de pequeno porte. Trata-se de um dado importante, pois indica que os conselhos foram criados exatamente como foi prescrito pelo ECA. Na área da saúde, a legislação recomenda a distribuição de $50 \%$ das cadeiras para os usuários e as demais distribuídas entre os outros segmentos, sendo $25 \%$ para trabalhadores e $25 \%$ para gestores e prestadores. A maioria dos conselhos segue a legislação, pois 7 entre 10 deles nos municípios de médio porte, e 8 entre 10 nos municípios de pequeno porte possuem essa distribuição. Na área da assistência social, a distribuição está bem concentrada na forma paritária entre governo e sociedade civil, sendo, portanto, a única área na qual a distribuição entre os segmentos se diferencia do que está preconizado na legislação, pois não há a presença dos trabalhadores e usuários da política.

Observa-se que o tamanho de cidade é uma variável que não distingue os conselhos, ao contrário da variável tipo de política pública, que prevê na própria legislação uma distinção.

Quanto à pluralidade, é possível identificar atores importantes para a formulação das políticas, principalmente os usuários da política de saúde. Na área da assistência social, é comum a presença dos usuários, mas isso não se reproduziu nos conselhos pesquisados. A ausência de usuários nos CMDCAs pode ser vista como uma limitação em relação às demais áreas. Já existe, em alguns programas destinados a esse público, uma discussão acerca do protagonismo infantojunevil, por meio do qual se busca ouvir e integrar as crianças e adolescentes nos processos decisórios sobre as políticas. Os conselhos teriam a se beneficiar com essa discussão, mas ainda não têm promovido ações nesse sentido. Isso pode ser visto como um problema de legitimidade das decisões produzidas por esse conselho, na medida em que o público diretamente afetado pelas políticas não participa do processo decisório. Essa é a base do chamado princípio $D$ habermasiano, que se tornou um dos principais postulados da teoria democrática deliberativa (HABERMAS, 2003; PARKINSON, 2006; YOUNG, 2000). 
No que se refere ao número de membros componentes dos conselhos - Tabela 7 -, é possível observar uma grande concentração de conselhos que possuem entre 10 a 20 membros. Por um lado, um número maior de membros pode indicar uma pluralidade e heterogeneidade mais elevada entre os conselheiros. Por outro, pode significar uma maior dificuldade de se estabelecer uma dinâmica realmente deliberativa no interior desse fórum. Aliteratura indica que a deliberação é propiciada pela formação de pequenos grupos e, ao contrário, limitada pela ampliação de participantes. Trata-se do problema da escala abordado por Parkinson (2006), quando indica a existência de uma contradição estrutural no postulado principal da teoria democrática deliberativa, segundo a qual são legítimas apenas aquelas decisões que contaram com a participação (ou abertura da possibilidade) de todos aqueles possivelmente afetados por elas. Isso seria, no entanto, impossível, uma vez que a deliberação só poder ser realizada em pequenos grupos. Portanto, apesar de a presença de muitos membros no fórum deliberativo aumentar a possibilidade de que ele que seja mais representativo, grupos maiores do que 15-20 integrantes podem prejudicar a qualidade do processo decisório. Quando se compara pelo tamanho de cidade, observa-se uma distribuição bem similar entre os municípios de médio e de pequeno porte. Ambos possuem a maior parte de conselhos com o número de 10 a 20 membros, no total de 19 conselhos nos dois tipos de cidades. Isso representa 70,37\% do total de conselhos nas cidades de médio porte e 73,07\% nos municípios de pequeno porte.

Tabela 7 - Quantidade de conselhos por número de membros

\begin{tabular}{c|c|c|c|c|c|c|c|c|c}
\hline $\begin{array}{c}\text { Cidades } \\
\text { de mé- } \\
\text { dio porte }\end{array}$ & $\begin{array}{c}\text { Menos } \\
\text { de 10 } \\
\text { membros }\end{array}$ & $\begin{array}{c}\text { De } 10 \\
\text { a 20 } \\
\text { membros }\end{array}$ & $\begin{array}{c}\text { De 21 } \\
\text { a 60 } \\
\text { membros }\end{array}$ & $\begin{array}{c}\text { Total de } \\
\text { conselhos }\end{array}$ & $\begin{array}{c}\text { Cidades } \\
\text { de } \\
\text { pequeno } \\
\text { porte }\end{array}$ & $\begin{array}{c}\text { Menos } \\
\text { de 10 } \\
\text { mem- } \\
\text { bros }\end{array}$ & $\begin{array}{c}\text { De 10 } \\
\text { a 20 } \\
\text { mem- } \\
\text { bros }\end{array}$ & $\begin{array}{c}\text { De 21 a } \\
\mathbf{6 0} \text { mem- } \\
\text { bros }\end{array}$ & $\begin{array}{c}\text { Total } \\
\text { de con- } \\
\text { selhos }\end{array}$ \\
\hline $\begin{array}{c}\text { Juiz de } \\
\text { Fora }\end{array}$ & 0 & 2 & 1 & 3 & $\begin{array}{c}\text { Alpinópo- } \\
\text { lis }\end{array}$ & 0 & 3 & 0 & 3 \\
\hline $\begin{array}{c}\text { Poços de } \\
\text { Caldas }\end{array}$ & 1 & 1 & 1 & 3 & Alvinópolis & 0 & 0 & 1 & 1 \\
\hline $\begin{array}{c}\text { Petrópo- } \\
\text { lis }\end{array}$ & 0 & 2 & 1 & 3 & Arinos & 1 & 1 & 0 & 2 \\
\hline $\begin{array}{c}\text { Volta } \\
\text { Redonda }\end{array}$ & 0 & 2 & 0 & 2 & $\begin{array}{c}\text { Belo Ori- } \\
\text { ente }\end{array}$ & 1 & 2 & 0 & 3 \\
\hline $\begin{array}{c}\text { Cubatão } \\
\text { Lages }\end{array}$ & 0 & 3 & 0 & 3 & $\begin{array}{c}\text { Bom } \\
\text { Sucesso }\end{array}$ & 1 & 2 & 0 & 3 \\
\hline Chapecó & 0 & 2 & 1 & 3 & $\begin{array}{c}\text { Carmo do } \\
\text { Cajuru }\end{array}$ & 1 & 1 & 0 & 2 \\
\hline
\end{tabular}




\begin{tabular}{|c|c|c|c|c|c|c|c|c|c|}
\hline $\begin{array}{c}\text { São Leo- } \\
\text { poldo }\end{array}$ & 0 & 1 & 1 & 2 & $\begin{array}{c}\text { Carmo do } \\
\text { Rio Claro }\end{array}$ & 0 & 3 & 0 & 3 \\
\hline Anápolis & 0 & 3 & 0 & 3 & $\begin{array}{l}\text { Chapada } \\
\text { do Norte }\end{array}$ & 2 & 0 & 0 & 2 \\
\hline $\begin{array}{c}\text { Águas } \\
\text { Lindas de } \\
\text { Goiás } \\
\end{array}$ & 1 & 1 & 0 & 2 & \begin{tabular}{|c|}
$\begin{array}{c}\text { Conceição } \\
\text { das Ala- } \\
\text { goas }\end{array}$ \\
\end{tabular} & 0 & 1 & 0 & 1 \\
\hline- & - & - & - & - & $\begin{array}{c}\text { Monte } \\
\text { Alegre de } \\
\text { Minas }\end{array}$ & 0 & 3 & 0 & 3 \\
\hline $\begin{array}{c}\text { Total } \\
\text { (Cidades } \\
\text { médias) }\end{array}$ & 2 & 19 & 6 & 27 & $\begin{array}{c}\text { Total } \\
\text { (Cidades } \\
\text { pequenas) }\end{array}$ & 6 & 19 & 1 & 26 \\
\hline
\end{tabular}

Fonte: AVRITZER et al, 2013.

No que se refere à distribuição do poder entre os membros do conselho, é importante analisar quais são a prerrogativas da presidência do conselho. $O$ intuito é analisar se as regras concentram o poder decisório nas mãos do presidente ou se dispersam esse poder entre os conselheiros ou outras instâncias do próprio conselho. Se existe uma proporcionalidade entre os segmentos componentes do conselho, isso pode indicar uma distribuição "igualitária" da possibilidade de aprovação das questões prioritárias para cada segmento. É importante analisar, concomitantemente, quem pode ocupar a presidência do conselho, e qual é o poder a ele conferido para o exercício de sua função. Se as questões centrais dos conselhos, tais como a definição da agenda e as prerrogativas como o voto de minerva e a aprovação ad referendum estiverem concentradas na presidência, criase um desequilíbrio entre os segmentos.

Tabela 8 - Prerrogativas da presidência

\begin{tabular}{|c|c|c|c|c|c|c|c|c|c|c|}
\hline & \multicolumn{6}{|c|}{ Número de conselhos por processo de votação } & \multicolumn{4}{|c|}{ Total } \\
\hline & \multicolumn{2}{|c|}{ CMS } & \multicolumn{2}{|c|}{ CMAS } & \multicolumn{2}{|c|}{ CMDCA } & \multicolumn{2}{|c|}{$\begin{array}{c}\text { Cidades } \\
\text { de médio } \\
\text { porte }\end{array}$} & \multicolumn{2}{|c|}{$\begin{array}{c}\text { Cidades de } \\
\text { pequeno } \\
\text { porte }\end{array}$} \\
\hline & \begin{tabular}{|c|} 
Cidades \\
de \\
médio \\
porte
\end{tabular} & $\begin{array}{c}\text { Cidades } \\
\text { de } \\
\text { pequeno } \\
\text { porte }\end{array}$ & $\begin{array}{c}\text { Cidades } \\
\text { de } \\
\text { médio } \\
\text { porte }\end{array}$ & $\begin{array}{c}\text { Cidades } \\
\text { de } \\
\text { pequeno } \\
\text { porte }\end{array}$ & $\begin{array}{c}\text { Cidades } \\
\text { de } \\
\text { médio } \\
\text { porte }\end{array}$ & $\begin{array}{c}\text { Cidades } \\
\text { de } \\
\text { pequeno } \\
\text { porte }\end{array}$ & $\mathbf{N}$ & $\%$ & $\mathbf{N}$ & $\%$ \\
\hline $\begin{array}{l}\text { Voto de } \\
\text { minerva/de- } \\
\text { sempate }^{1}\end{array}$ & 4 & 2 & 1 & 3 & 1 & 2 & 6 & 16,67 & 7 & 24,14 \\
\hline $\begin{array}{l}\text { Não existe } \\
\text { prerrogativa }\end{array}$ & 3 & 4 & 2 & 2 & 2 & 2 & 7 & 19,44 & 8 & 27,59 \\
\hline
\end{tabular}




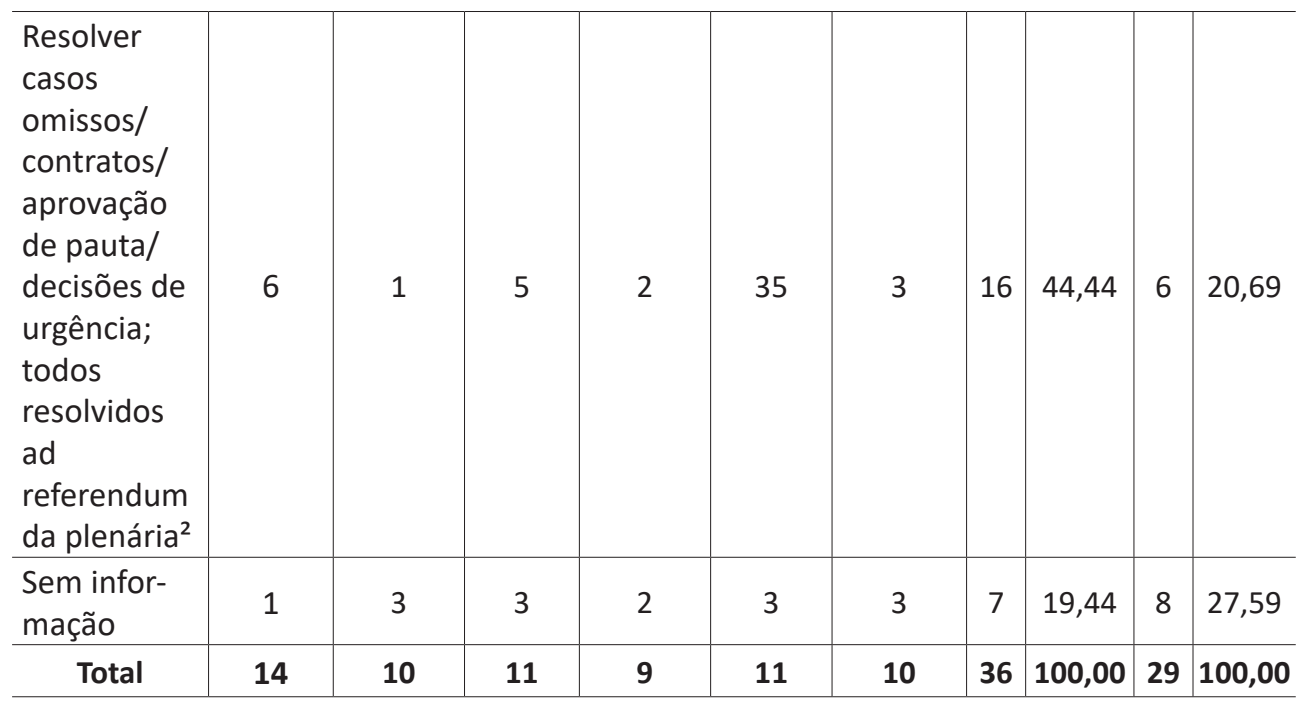

${ }^{1} O$ voto de minerva e de desempate garante ao presidente o poder de definir a votação em caso de empate. ${ }^{2}$ Foram agregadas todas as variáveis relativas ao poder de deliberar ad referendum pela presidência. Fonte: AVRITZER et al, 2013.

A análise da Tabela 8 indica concentração de poder, expresso na possibilidade de dar encaminhamentos e produzir decisões ad referendum. Tal situação está presente em 16 (44,44\%) dos 36 conselhos das cidades de médio porte, e em 6 (20,69\%) dos 29 conselhos das cidades de pequeno porte. Destaca-se, nesse quesito, o CMDCA das cidades de médio porte, nos quais esse mecanismo está presente em aproximadamente $45 \%$ dos casos. De um modo geral, portanto, é possível afirmar a existência de uma concentração de poder nas mãos dos presidentes, conferida pela possibilidade de aprovar as questões ad referendum e pela existência do voto de minerva. Não é possível observar diferenças significativas entre os conselhos derivadas das variáveis: 1) tamanho de cidade; e 2) tipo de política pública. Resta saber se existe um rodízio entre os segmentos que ocupam esse cargo. Veja-se o que dizem as leis a esse respeito na Tabela 9.

Tabela 9 - Quem pode presidir o conselho

\begin{tabular}{l|c|c|c|c|c|c|c|c}
\hline & \multicolumn{3}{|c|}{ Número de conselhos por quem pode assumir a } & \multicolumn{3}{c}{ Total } \\
presidência
\end{tabular}




\begin{tabular}{|c|c|c|c|c|c|c|c|c|c|c|}
\hline $\begin{array}{l}\text { Apenas o } \\
\text { secretário } \\
\text { municipal }\end{array}$ & 1 & 4 & 0 & 0 & 0 & 0 & 1 & 3,45 & 4 & 13,79 \\
\hline $\begin{array}{l}\text { Qualquer } \\
\text { conselheiro } \\
\text { eleito em } \\
\text { assembleia }\end{array}$ & 6 & 2 & 7 & 7 & 8 & 4 & 21 & 72,41 & 13 & 44,83 \\
\hline $\begin{array}{l}\text { Qualquer } \\
\text { membro do } \\
\text { conselho } \\
\text { eleito c/ } \\
\text { alternância } \\
\text { bianual }\end{array}$ & 0 & 0 & 0 & 1 & 1 & 0 & 1 & 3,45 & 1 & 3,45 \\
\hline $\begin{array}{l}\text { Presidência } \\
\text { representante } \\
\text { da soc. } \\
\text { civil e vice- } \\
\text { presidência } \\
\text { governo }\end{array}$ & 0 & 0 & 0 & 0 & 0 & 1 & 0 & 0,00 & 1 & 3,45 \\
\hline $\begin{array}{c}\text { Sem } \\
\text { informação }\end{array}$ & 2 & 4 & 3 & 1 & 1 & 5 & 6 & 20,69 & 10 & 34,48 \\
\hline Total & 9 & 10 & 10 & 9 & 10 & 10 & 29 & 100,00 & 29 & 100,00 \\
\hline
\end{tabular}

Fonte: AVRITZER et al, 2013.

Percebe-se uma concentração muito expressiva de $72,41 \%$ dos casos, nas cidades de médio porte, em que é conferida a qualquer conselheiro a possibilidade de ser eleito o presidente, com destaque para o CMDCA, em que a maioria dos casos (8 em 10 nas cidades de médio porte e 4 em 10 nas cidades de pequeno porte) apresenta essa condição. As regras nos dois tipos de municípios são bem democráticas, pois permitem que a presidência possa ser ocupada por qualquer conselheiro, sendo mais expressiva essa regra nos municípios de médio porte. Quando se reduz o tamanho da cidade diminui o potencial democrático da instituição. Importante destacar, ainda, a presença da alternância na presidência entre governo e sociedade civil.

Os CMDCAs das cidades de médio porte são muito democráticos. Nas cidades de pequeno porte essa situação é similar, pois qualquer conselheiro pode se tornar presidente. Nesses municípios, no entanto, o número de casos sem informação (5 em 10) é muito grande. Esse dado pode indicar a existência de um regimento pouco aprimorado, na medida em que omite uma regra tão relevante e importante quanto a forma de escolha da presidência. Outra questão muito importante a ser analisada é o processo decisório estabelecido no regimento, como nos mostra a Tabela 10. 
Tabela 10 - Processo de votação

\begin{tabular}{|c|c|c|c|c|c|c|c|c|c|c|}
\hline & \multicolumn{6}{|c|}{ Número de conselhos por processo de votação } & \multicolumn{4}{|c|}{ Total } \\
\hline & \multicolumn{2}{|c|}{ CMS } & \multicolumn{2}{|c|}{ CMAS } & \multicolumn{2}{|c|}{ CMDCA } & \multicolumn{2}{|c|}{$\begin{array}{c}\text { Cidades de } \\
\text { médio porte }\end{array}$} & \multicolumn{2}{|c|}{$\begin{array}{c}\text { Cidades de } \\
\text { pequeno } \\
\text { porte }\end{array}$} \\
\hline & $\begin{array}{c}\text { Cidades } \\
\text { de médio } \\
\text { porte }\end{array}$ & $\begin{array}{c}\text { Cidades } \\
\text { de } \\
\text { pequeno } \\
\text { porte }\end{array}$ & $\begin{array}{c}\text { Cidades } \\
\text { de } \\
\text { médio } \\
\text { porte }\end{array}$ & $\begin{array}{c}\text { Cidades } \\
\text { de } \\
\text { pequeno } \\
\text { porte }\end{array}$ & $\begin{array}{c}\text { Cidades } \\
\text { de } \\
\text { médio } \\
\text { porte }\end{array}$ & $\begin{array}{c}\text { Cidades } \\
\text { de } \\
\text { pequeno } \\
\text { porte }\end{array}$ & $\mathbf{N}$ & $\%$ & $\mathbf{N}$ & $\%$ \\
\hline $\begin{array}{l}\text { Votação } \\
\text { por maio- } \\
\text { ria sim- } \\
\text { ples }\end{array}$ & 7 & 4 & 5 & 4 & 4 & 0 & 16 & 55,17 & 8 & 27,59 \\
\hline $\begin{array}{c}\text { Maioria } \\
\text { absoluta }\end{array}$ & 0 & 0 & 0 & 1 & 3 & 1 & 3 & 10,34 & 2 & 6,90 \\
\hline $\begin{array}{c}\text { Sem in- } \\
\text { formação' }\end{array}$ & 2 & 6 & 5 & 4 & 3 & 9 & 10 & 34,48 & 19 & 65,52 \\
\hline Total & 9 & 10 & 10 & 9 & 10 & 10 & 29 & 100,00 & 29 & 100,00 \\
\hline
\end{tabular}

${ }^{1}$ Os casos que não apresentam informações, provavelmente devem operar por maioria simples. Fonte: AVRITZER et al, 2013.

É possível observar uma concentração de casos cujo processo de votação é realizado por meio de maioria simples. Nesse sentido, temos $55,17 \%$ dos conselhos das cidades de médio porte e $27,59 \%$ das cidades de pequeno porte. Apesar de ser grande o número de conselhos sem informações nas outras áreas de políticas públicas, os CMDCAs dos municípios de pequeno porte indicam a situação mais precária a esse respeito, pois não se tem explícito nos documentos do conselho este que é um princípio estruturante de todo e qualquer processo decisório. Possivelmente, adota-se algum mecanismo decisório informal nesses conselhos. 
Tabela 11 - Quem define a pauta

\begin{tabular}{|c|c|c|c|c|c|c|c|c|c|c|}
\hline & \multicolumn{6}{|c|}{ Número de conselhos por definição de pauta } & \multicolumn{4}{|c|}{ Total } \\
\hline & \multicolumn{2}{|c|}{ CMS } & \multicolumn{2}{|c|}{ CMAS } & \multicolumn{2}{|c|}{ CMDCA } & \multicolumn{2}{|c|}{$\begin{array}{c}\text { Total Ci- } \\
\text { dades de } \\
\text { médio porte }\end{array}$} & \multicolumn{2}{|c|}{$\begin{array}{c}\text { Total Ci- } \\
\text { dades de } \\
\text { pequeno } \\
\text { porte }\end{array}$} \\
\hline & $\begin{array}{c}\text { Cidades } \\
\text { de mé- } \\
\text { dio porte }\end{array}$ & $\begin{array}{c}\text { Cidades } \\
\text { de } \\
\text { pequeno } \\
\text { porte }\end{array}$ & $\begin{array}{c}\text { Cidades } \\
\text { de } \\
\text { médio } \\
\text { porte }\end{array}$ & $\begin{array}{c}\text { Cidades } \\
\text { de } \\
\text { pequeno } \\
\text { porte }\end{array}$ & $\begin{array}{l}\text { Cidades } \\
\text { de } \\
\text { médio } \\
\text { porte }\end{array}$ & $\begin{array}{c}\text { Cidades } \\
\text { de } \\
\text { pequeno } \\
\text { porte }\end{array}$ & $\mathbf{N}$ & $\%$ & $\mathbf{N}$ & $\%$ \\
\hline $\begin{array}{c}\text { O presi- } \\
\text { dente }\end{array}$ & 0 & 0 & 1 & 0 & 1 & 3 & 2 & 6,90 & 3 & 10,34 \\
\hline $\begin{array}{l}\text { Mesa dire- } \\
\text { tora e/ou } \\
\text { secretaria } \\
\text { executiva }\end{array}$ & 5 & 1 & 0 & 2 & 6 & 0 & 11 & 37,93 & 3 & 10,34 \\
\hline $\begin{array}{c}\text { Pauta } \\
\text { definida } \\
\text { em reunião } \\
\text { anterior } \\
\text { pelos con- } \\
\text { selheiros }\end{array}$ & 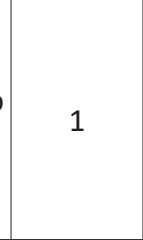 & 2 & 2 & 1 & 0 & 0 & 3 & 10,34 & 3 & 10,34 \\
\hline Outros & 1 & 2 & 1 & 1 & 0 & 1 & 2 & 6,90 & 4 & 13,79 \\
\hline $\begin{array}{l}\text { Sem infor- } \\
\text { mação }\end{array}$ & 2 & 5 & 6 & 5 & 3 & 6 & 11 & 37,93 & 16 & 55,17 \\
\hline Total & 9 & 10 & 10 & 9 & 10 & 10 & 29 & 100,00 & 29 & 100,00 \\
\hline
\end{tabular}

Fonte: AVRITZER et al, 2013.

A análise da Tabela 11 nos permite afirmar ser a mesa diretora e/ou a secretaria executiva a principal definidora da pauta nos conselhos das cidades de médio porte, com 37,93\% dos casos. Sobressai-se, nesse quesito, o CMDCA nos municípios de médio porte. Outra situação correlata relacionada ao processo decisório dos conselhos diz respeito aos atores autorizados ou não pelo regimento interno para propor mudanças nas pautas das reuniões dessas instituições. Nesse sentido, se estar autorizado a incluir uma questão para discussão é um elemento que pode diferenciar o acesso aos recursos de poder no interior das instituições, poder excluir ou alterar o conteúdo da pauta é, também, um instrumento de poder significativo. Por isso, é importante observar quais os atores que podem alterar a pauta já estabelecida. Vejamos quais são esses atores a partir da análise da Tabela 12. 
Tabela 12 - Mudança de pauta

\begin{tabular}{|c|c|c|c|c|c|c|}
\hline & \multicolumn{2}{|c|}{ CMS } & \multicolumn{2}{|c|}{ CMDCA } & \multicolumn{2}{|c|}{ Total } \\
\hline & $\begin{array}{l}\text { Cidade } \\
\text { de médio } \\
\text { porte }\end{array}$ & $\begin{array}{l}\text { Cidade de } \\
\text { pequeno } \\
\text { porte }\end{array}$ & $\begin{array}{c}\text { Cidade } \\
\text { de médio } \\
\text { porte }\end{array}$ & $\begin{array}{c}\text { Cidade de } \\
\text { pequeno } \\
\text { porte }\end{array}$ & $\begin{array}{c}\text { Cidade } \\
\text { de médio } \\
\text { porte }\end{array}$ & $\begin{array}{c}\text { Cidade } \\
\text { de } \\
\text { pequeno } \\
\text { porte }\end{array}$ \\
\hline $\begin{array}{l}\text { Conselheiros na } \\
\text { reunião }\end{array}$ & 1 & 0 & 1 & 0 & 2 & 1 \\
\hline $\begin{array}{l}\text { Conselheiros ou } \\
\text { secretaria durante } \\
\text { a reunião com } \\
\text { aprovação }\end{array}$ & 2 & 1 & 0 & 0 & 2 & 2 \\
\hline $\begin{array}{l}\text { Moções, denúncias, } \\
\text { indicação ou } \\
\text { requerimento ou } \\
\text { urgência }\end{array}$ & 0 & 0 & 1 & 0 & 1 & 1 \\
\hline $\begin{array}{c}\text { Conselheiros por } \\
\text { escrito encaminhado à } \\
\text { Mesa Diretora }\end{array}$ & 0 & 1 & 0 & 0 & 0 & 1 \\
\hline $\begin{array}{l}\text { Fim da reunião/ } \\
\text { matéria urgente }\end{array}$ & 0 & 1 & 0 & 0 & 0 & 1 \\
\hline $\begin{array}{l}\text { Coordenador/ } \\
\text { Presidente }\end{array}$ & 0 & 1 & 1 & 0 & 1 & 1 \\
\hline $\begin{array}{c}2 / 3 \text { de presença e } \\
\text { aprovação por maioria } \\
\text { simples }\end{array}$ & 0 & 6 & 0 & 10 & 0 & 22 \\
\hline Sem informação & 6 & 0 & 7 & 0 & 23 & 1 \\
\hline Total & 9 & 10 & 10 & 10 & 29 & 29 \\
\hline
\end{tabular}

Fonte: AVRITZER et al, 2013.

Dois elementos chamam a atenção. Primeiramente, o número muito elevado de casos sem informação, 23, nas cidades de médio porte. 0 segundo é a elevada concentração de conselhos das cidades de pequeno porte, 22, que adotam como regra a necessidade da presença de $2 / 3$ dos conselheiros e a aprovação por maioria simples para se alterar as questões de pauta. Nesse quesito, destaca-se o CMDCA, pois a totalidade dos conselhos (10 em 10) das cidades de pequeno porte adota essa regra como condição para mudança na pauta. Nesse sentido, existe uma relativa dificuldade de se alterar as questões incluídas na pauta. Essa regra reforça o poder da presidência, da mesa diretora/secretaria executiva, na medida em que a exigência para alteração das questões exige elevada presença e aprovação por maioria simples. Uma última questão relacionada às normas de interação entre os conselheiros diz respeito às regras de modificação do RI, como nos mostra a Tabela 13. 
Tabela 13 - Regras de modificação do RI

\begin{tabular}{|c|c|c|c|c|c|c|c|c|c|c|}
\hline & \multicolumn{6}{|c|}{ Número de conselhos por modificação do RI } & \multicolumn{4}{|c|}{ Total } \\
\hline & \multicolumn{2}{|c|}{ CMS } & \multicolumn{2}{|c|}{ CMAS } & \multicolumn{2}{|c|}{ CMDCA } & \multicolumn{2}{|c|}{$\begin{array}{l}\text { Cidade } \\
\text { de médio } \\
\text { porte }\end{array}$} & \multicolumn{2}{|c|}{$\begin{array}{c}\text { Cidade de } \\
\text { pequeno } \\
\text { porte }\end{array}$} \\
\hline & $\begin{array}{l}\text { Cidade } \\
\text { de } \\
\text { médio } \\
\text { porte }\end{array}$ & $\begin{array}{c}\text { Cidade } \\
\text { de } \\
\text { pequeno } \\
\text { porte }\end{array}$ & \begin{tabular}{|c|} 
Cidade \\
de \\
médio \\
porte
\end{tabular} & $\begin{array}{c}\text { Cidade } \\
\text { de } \\
\text { pequeno } \\
\text { porte }\end{array}$ & $\begin{array}{l}\text { Cidade } \\
\text { de } \\
\text { médio } \\
\text { porte }\end{array}$ & $\begin{array}{c}\text { Cidade } \\
\text { de } \\
\text { pequeno } \\
\text { porte }\end{array}$ & $\mathbf{N}$ & $\%$ & $\mathbf{N}$ & $\%$ \\
\hline $\begin{array}{c}\text { Consel- } \\
\text { heiros c/ } \\
\text { proposição } \\
\text { e aprovação }\end{array}$ & 0 & 2 & 0 & 0 & 2 & 1 & 2 & 6,90 & 3 & 10,34 \\
\hline $\begin{array}{c}\text { Consel- } \\
\text { heiros } \\
\text { c/ pro- } \\
\text { porção de } \\
\text { aprovação }\end{array}$ & 7 & 4 & 5 & 3 & 6 & 2 & 18 & 62,07 & 9 & 31,03 \\
\hline $\begin{array}{l}\text { Consel- } \\
\text { heiros s/ } \\
\text { criterios e } \\
\text { proporção }\end{array}$ & 0 & 1 & 0 & 0 & 0 & 0 & 0 & 0,00 & 1 & 3,45 \\
\hline $\begin{array}{l}\text { Sem infor- } \\
\text { mação }\end{array}$ & 2 & 3 & 5 & 6 & 2 & 7 & 9 & 31,03 & 16 & 55,17 \\
\hline Total & 9 & 10 & 10 & 9 & 10 & 10 & 29 & 100,00 & 29 & 100,00 \\
\hline
\end{tabular}

Fonte: AVRITZER et al, 2013.

A maior concentração de casos está no seguinte item: conselheiros com proporção de aprovação, sendo adotada por 62,07 \% dos conselhos das cidades de médio porte e $31,03 \%$ das cidades de pequeno porte. Uma tendência geral nos conselhos das três áreas é o aumento do número de casos sem informação quando se reduz o tamanho de cidade. Uma visão de conjunto permite afirmar, portanto, que a modificação do RI depende, geralmente, da aprovação dos conselheiros e pode ser iniciada, principalmente, pelos próprios conselheiros.

Uma análise do conjunto das variáveis analisadas neste tópico permite afirmar a existência de regras, em princípio, favoráveis à democratização dos conselhos. No que se refere ao número de membros, a maior parte possuiu entre 10 e 20 membros, o que pode ser visto como número razoável para assegurar certa pluralidade de atores e, ao mesmo tempo, permitir condições propícias para a realização dos processos deliberativos, dependentes da constituição de pequenos grupos.

De um modo geral, tipo de política pública não é um elemento importante para distinguir os conselhos. Por outro lado, a redução no tamanho de cidade implica, geralmente, na ausência de informações importantes acerca do processo decisório dos conselhos. Passemos à análise da representatividade dos conselhos. 


\section{Desenho institucional e representatividade}

A maioria dos conselhos é composta por representantes do governo e da sociedade civil. Os representantes do governo são, em geral, indicados pelos governantes eleitos pela população. Os conselheiros da sociedade civil são escolhidos por processos variados, pois as regras são estabelecidas por cada um dos conselhos. Uma questão comum, que perpassa a quase totalidade dos conselhos, é o fato de os representantes da sociedade civil serem escolhidos entre entidades que desempenham atividades na área de política pública do conselho. Assim, a sociedade é representada nos conselhos por coletividades e não indivíduos isolados.

Buscou-se identificar no RI se havia a previsão de categorias de entidades da sociedade civil para atuarem como representantes da sociedade nos conselhos. Os dados estão sistematizados na Tabela 14.

Tabela 14 - Previsão de categorias de entidades representantes da sociedade civil

\begin{tabular}{|c|c|c|c|c|c|c|c|c|c|c|}
\hline & \multicolumn{6}{|c|}{$\begin{array}{l}\text { Número de conselhos por previsão de categoria da } \\
\text { sociedade civil }\end{array}$} & \multicolumn{4}{|c|}{ Total } \\
\hline & \multicolumn{2}{|c|}{ CMS } & \multicolumn{2}{|c|}{ CMAS } & \multicolumn{2}{|c|}{ CMDCA } & \multicolumn{2}{|c|}{$\begin{array}{c}\text { Cidade de } \\
\text { médio porte }\end{array}$} & \multicolumn{2}{|c|}{$\begin{array}{c}\text { Cidade de } \\
\text { pequeno } \\
\text { porte }\end{array}$} \\
\hline & $\begin{array}{c}\text { Cidade } \\
\text { de médio } \\
\text { porte }\end{array}$ & $\begin{array}{c}\text { Cidade } \\
\text { de } \\
\text { pequeno } \\
\text { porte }\end{array}$ & $\begin{array}{l}\text { Cidade } \\
\text { de } \\
\text { médio } \\
\text { porte }\end{array}$ & $\begin{array}{c}\text { Cidade } \\
\text { de } \\
\text { pequeno } \\
\text { porte }\end{array}$ & $\begin{array}{l}\text { Cidade } \\
\text { de } \\
\text { médio } \\
\text { porte }\end{array}$ & $\begin{array}{c}\text { Cidade } \\
\text { de } \\
\text { pequeno } \\
\text { porte }\end{array}$ & N & $\%$ & $\mathbf{N}$ & $\%$ \\
\hline Não & 1 & 6 & 5 & 5 & 7 & 6 & 13 & 44,83 & 17 & 58,62 \\
\hline Sim & 8 & 4 & 4 & 1 & 3 & 1 & 15 & 51,72 & 6 & 20,69 \\
\hline $\begin{array}{l}\text { Sem } \\
\text { infor- } \\
\text { mação }\end{array}$ & 0 & 0 & 1 & 3 & 0 & 3 & 1 & 3,45 & 6 & 20,69 \\
\hline Total & 9 & 10 & 10 & 9 & 10 & 10 & 29 & 100,00 & 29 & 100,00 \\
\hline
\end{tabular}

Fonte: AVRITZER et al, 2013.

Observa-se que $44,83 \%$ dos conselhos das cidades de médio porte e $58,62 \%$ nas cidades de pequeno porte não preveem entidades da sociedade civil para atuarem como representantes. Por outro lado, $51,72 \%$ dos conselhos das cidades de médio porte preveem entidades da sociedade civil, e $20,69 \%$ nas cidades de pequeno porte. A maioria dos CMDCAs não prevê entidades da sociedade civil. Diante desse fato é difícil saber quais atores estão representando a sociedade naqueles conselhos, tal como preconizado pelo ECA. Uma informação possível para responder a essa questão é aquela relativa ao modo como são selecionados os representantes da sociedade civil. A Tabela 15 sistematiza esses dados. 
Percebe-se um alto percentual de casos nos quais existe eleição em assembleia ou fórum para a definição dos representantes da sociedade civil. Essa é a situação de $27,59 \%$ dos conselhos das cidades de médio porte, e $41,38 \%$ das cidades de pequeno porte, ou seja, existe uma elevação do número de conselhos que realizam eleição quando se passa dos municípios maiores para os menores.

É possível observar uma diferença entre os conselhos, em função do tipo de política pública, pois os CMDCAs são os mais democráticos, já que elegem os representantes da sociedade civil em fóruns ou assembleias e no próprio conselho. As outras duas áreas de políticas possuem um grande número de casos sem informação sobre o processo de escolha dos representantes da sociedade civil. Em relação ao tamanho de cidade, a eleição como processo de escolha está presente em maior número nos municípios de pequeno porte.

Tabela 15 - Como são definidos os representantes da sociedade civil

\begin{tabular}{|c|c|c|c|c|c|c|c|c|c|c|}
\hline & \multicolumn{6}{|c|}{$\begin{array}{l}\text { Número de conselhos por definição de conselheiros } \\
\text { da sociedade civil }\end{array}$} & \multicolumn{4}{|c|}{ Total } \\
\hline & \multicolumn{2}{|c|}{ CMS } & \multicolumn{2}{|c|}{ CMAS } & \multicolumn{2}{|c|}{ CMDCA } & \multicolumn{2}{|c|}{$\begin{array}{l}\text { Cidade de } \\
\text { médio porte }\end{array}$} & \multicolumn{2}{|c|}{$\begin{array}{c}\text { Cidade de } \\
\text { pequeno } \\
\text { porte }\end{array}$} \\
\hline & $\begin{array}{l}\text { Cidade } \\
\text { de } \\
\text { médio } \\
\text { porte }\end{array}$ & $\begin{array}{c}\text { Cidade } \\
\text { de } \\
\text { pequeno } \\
\text { porte }\end{array}$ & $\begin{array}{l}\text { Cidade } \\
\text { de } \\
\text { médio } \\
\text { porte }\end{array}$ & $\begin{array}{c}\text { Cidade } \\
\text { de } \\
\text { pequeno } \\
\text { porte }\end{array}$ & $\begin{array}{c}\text { Cidade } \\
\text { de } \\
\text { médio } \\
\text { porte }\end{array}$ & $\begin{array}{c}\text { Cidade } \\
\text { de } \\
\text { peque- } \\
\text { no } \\
\text { porte }\end{array}$ & $\mathbf{N}$ & $\%$ & $\mathbf{N}$ & $\%$ \\
\hline $\begin{array}{c}\text { Eleito em } \\
\text { assembleia ou } \\
\text { fórum } \\
\end{array}$ & 0 & 3 & 2 & 2 & 6 & 7 & 8 & 27,59 & 12 & 41,38 \\
\hline $\begin{array}{l}\text { Indicado na } \\
\text { entidade ou } \\
\text { pelo Poder } \\
\text { Executivo }\end{array}$ & 1 & 0 & 3 & 0 & 0 & 1 & 4 & 13,79 & 1 & 3,45 \\
\hline $\begin{array}{c}\text { Eleito em } \\
\text { assembleia do } \\
\text { conselho } \\
\end{array}$ & 0 & 0 & 0 & 0 & 0 & 1 & 0 & 0,00 & 1 & 3,45 \\
\hline $\begin{array}{c}\text { Eleição em } \\
\text { assembleia } \\
\text { pública }\end{array}$ & 0 & 0 & 0 & 1 & 0 & 0 & 0 & 0,00 & 1 & 3,45 \\
\hline $\begin{array}{c}\text { Eleito na enti- } \\
\text { dade }\end{array}$ & 1 & 0 & 0 & 0 & 1 & 0 & 2 & 6,90 & 0 & 0,00 \\
\hline $\begin{array}{c}\text { Indicado em } \\
\text { assembleia ou } \\
\text { fórum }\end{array}$ & 1 & 0 & 3 & 0 & 1 & 0 & 5 & 17,24 & 0 & 0,00 \\
\hline
\end{tabular}




\begin{tabular}{c|c|c|c|c|c|c|c|c|c|c}
\hline $\begin{array}{c}\text { Sem infor- } \\
\text { mação }\end{array}$ & 6 & 7 & 2 & 6 & 2 & 1 & 10 & 34,48 & 14 & 48,28 \\
\hline Total & $\mathbf{9}$ & $\mathbf{1 0}$ & $\mathbf{1 0}$ & $\mathbf{9}$ & $\mathbf{1 0}$ & $\mathbf{1 0}$ & $\mathbf{2 9}$ & $\mathbf{1 0 0 , 0 0}$ & $\mathbf{2 9}$ & $\mathbf{1 0 0 , 0 0}$ \\
\hline
\end{tabular}

Fonte: AVRITZER et al, 2013.

É importante destacar o grau muito elevado de conselhos que não possuem informação sobre o processo de escolha dos representantes da sociedade civil, $34,48 \%$ e $48,28 \%$ nas cidades de médio e pequeno porte, respectivamente. De um modo geral, a eleição é o principal mecanismo utilizado para escolher os representantes da sociedade civil. Trata-se de um processo de autorização democrático.

Vejamos como são definidos os conselheiros representantes do Poder Executivo, a partir das informações da Tabela 16 adiante. A indicação pelo Executivo aparece nos dois tipos de cidades como o procedimento mais utilizado, pois $62,07 \%$ dos conselhos adotam esse procedimento nos municípios de médio porte, ao passo que $44,83 \%$ utilizam esse mecanismo nas cidades de pequeno porte.

Tabela 16 - Como são definidos os conselhos representantes do Executivo

\begin{tabular}{|c|c|c|c|c|c|c|c|c|c|c|}
\hline & \multicolumn{6}{|c|}{$\begin{array}{c}\text { Número de conselhos por definição de representantes } \\
\text { do Executivo }\end{array}$} & \multicolumn{4}{|c|}{ Total } \\
\hline & \multicolumn{2}{|c|}{ CMS } & \multicolumn{2}{|c|}{ CMAS } & \multicolumn{2}{|c|}{ CMDCA } & \multicolumn{2}{|c|}{$\begin{array}{l}\text { Cidades } \\
\text { de médio } \\
\text { porte }\end{array}$} & \multicolumn{2}{|c|}{$\begin{array}{c}\text { Cidades de } \\
\text { pequeno } \\
\text { porte }\end{array}$} \\
\hline & \begin{tabular}{|c|} 
Cidades \\
de \\
médio \\
porte
\end{tabular} & $\begin{array}{c}\text { Cidades } \\
\text { de } \\
\text { pequeno } \\
\text { porte }\end{array}$ & $\begin{array}{c}\text { Cidades } \\
\text { de médio } \\
\text { porte }\end{array}$ & $\begin{array}{c}\text { Cidades } \\
\text { de } \\
\text { pequeno } \\
\text { porte }\end{array}$ & $\begin{array}{c}\text { Cidades } \\
\text { de } \\
\text { médio } \\
\text { porte }\end{array}$ & \begin{tabular}{|c|}
$\begin{array}{c}\text { Cidades } \\
\text { de } \\
\text { pequeno } \\
\text { porte }\end{array}$ \\
\end{tabular} & $\mathbf{N}$ & $\%$ & $\mathbf{N}$ & $\%$ \\
\hline $\begin{array}{l}\text { Indicado pelo } \\
\text { Executivo }\end{array}$ & 3 & 4 & 8 & 2 & 7 & 7 & 18 & 62,07 & 13 & 44,83 \\
\hline $\begin{array}{c}\text { Eleito em } \\
\text { fórum ou } \\
\text { conferência }\end{array}$ & 1 & 0 & 0 & 0 & 0 & 1 & 1 & 3,45 & 1 & 3,45 \\
\hline $\begin{array}{l}\text { Sem infor- } \\
\text { mação' }\end{array}$ & 5 & 6 & 2 & 7 & 3 & 2 & 10 & 34,48 & 15 & 51,72 \\
\hline Total & 9 & 10 & 10 & 9 & 10 & 10 & 29 & 100,00 & 29 & 100,00 \\
\hline
\end{tabular}

${ }_{1}^{1}$ Nos casos em que não se apresentam informações, provavelmente os conselheiros representantes do Poder Executivo são indicados pelo próprio Poder Executivo.

Fonte: AVRITZER et al, 2013.

Observando-se que os responsáveis pela indicação, os governantes eleitos, passaram por um processo de autorização da população, poderíamos considerar essa indicação do Executivo como uma forma indireta de autorização. Nesse sentido, teríamos algum mecanismo de autorização dos conselheiros da sociedade 
civil e do Estado. Ao analisar um conjunto de instituições deliberativas britânicas, John Parkinson (2006) sustenta a importância de se criarem mecanismos capazes de viabilizar os processos de accountability e de publicidade da ação dos representantes, pois os primeiros fariam com que eles agissem no melhor interesse dos seus representados, e os segundos tornariam acessível para a população quais ações foram desempenhadas pelos conselheiros. A combinação desses dois elementos teria como resultado uma atuação mais responsiva dos indivíduos envolvidos com as atividades das instituições deliberativas.

\section{Considerações finais}

Analisou-se no artigo um conjunto de dimensões características do desenho institucional dos conselhos de 59 cidades de médio e pequeno porte brasileiras. A despeito do fato de as cidades de pequeno porte representarem cerca de $70 \%$ dos municípios do país, ainda se sabe muito pouco a respeito da dinâmica política dessas localidades, em particular das instituições participativas, como os conselhos de políticas. A contribuição principal da pesquisa é problematizar como a composição e a atuação dos conselhos nas referidas cidades pode ser limitada pelos desafios e limites que encontram diante das disparidades territoriais e de escala que caracterizam o país.

Investigou-se um conjunto de indicadores do grau de institucionalização dos conselhos, das condições que oferecem à deliberação e, por fim, a questão da representatividade. Buscou-se verificar se seria possível diferenciar os conselhos em função do tamanho de cidade e do tipo de política pública (AVRITZER, 2010; LÜCHMAN, 2007). Cumpre destacar que a análise das regras apresentadas permite verificar somente as precondições estabelecidas para a dinâmica de funcionamento dessas instituições. Em outros termos, procurou-se descrever as características dessas instituições para identificar o grau de institucionalização das mesmas, bem como o seu potencial inclusivo e democratizante.

Os resultados sugerem constrangimentos à composição e à atuação dos conselhos nos municípios de pequeno porte, a despeito do fato de termos pesquisado áreas temáticas de políticas nas quais os conselhos tiveram "alta indução federal, ampla presença nos municípios do Brasil e elevado grau de integração a seus respectivos setores ou áreas de política" (LAVALLE; VoIGT; SERAFIM, 2016, p. 638). Os resultados da pesquisa robusta desenvolvida pelos autores citados indicam elevada capacidade decisória das três áreas de políticas aqui analisadas. Uma agenda futura de investigação inclui a realização de pesquisas em municípios de pequeno porte acerca dos resultados do trabalho dos conselhos. 
Conclui-se que os conselhos dos municípios componentes da amostra da pesquisa possuem características semelhantes, mas precisam ser investigados sob a ótica dos resultados que produzem. Existe um número significativo de conselhos com mais de dez anos de funcionamento, o que pode indicar um grau sólido de institucionalização de práticas e procedimentos. Além disso, a maioria deles realiza reuniões mensais, o que imprime regularidade às atividades da instituição.

A maioria dos conselhos possui entre 10 e 20 membros, um número razoável para assegurar a pluralidade da representação no conselho e, ao mesmo tempo, não inviabilizar os processos deliberativos desempenhados pela instituição, pois são os pequenos grupos que oferecem melhores condições para a deliberação.

A paridade entre os segmentos componentes do conselho existe na maioria dos conselhos, que adota uma composição na qual $50 \%$ dos conselheiros são oriundos do Estado e os outros 50\%, da sociedade civil. Essa subdivisão segue estritamente o que está preconizado na legislação para o caso dos CMDCAs. A definição da pauta pertence, em muitos casos, à mesa diretora/secretaria executiva. Um número significativo de casos menciona a definição em reunião anterior. Nas regras centrais para o processo decisório, vale destacar, foi identificado um percentual muito elevado de situações não previstas no regimento interno. Interpretamos essa informação como uma possível falta de qualificação, elaboração e aprimoramento do próprio regimento, principalmente nos municípios de pequeno porte.

De um modo geral, a redução no tamanho da cidade implicou em uma redução do nível de informação disponível sobre o desenho institucional dos conselhos, e em uma diminuição expressiva dos cinco componentes (plenário, mesa diretora, secretaria executiva, comissões e realização de conferências) da estrutura organizacional dos conselhos. No que se refere ao tipo de política pública, as variações não são tão expressivas quanto aquelas relacionadas ao tamanho da cidade.

\section{Referências bibliográficas}

AlmeidA, D. C. R.; CunhA, E. S. M. A análise da deliberação democrática: princípios, conceitos e variáveis relevantes. In: PIRES, Roberto Rocha C. (Org.). Efetividade das instituições participativas no Brasil: estratégias de avaliação. Brasília: Ipea, 2011. p. 109-124.

AlmeidA, D. C. Rezende. Metamorfoses da representação política. In: AVRITZER, Leonardo (Org.). A dinâmica da participação local no Brasil. São Paulo: Cortez, 2010. AlmeIDA, D. R.; CUNHA, Eleonora Schettini. Brazilian social assistance policy: an empirical test of the concept of deliberative systems. Critical Policy Studies, v. 1, p. 1-22, 2016.

AVRITZER, Leonardo; NAvARro, Zander (Orgs.). A inovação democrática no Brasil: o orçamento participativo. São Paulo: Cortez, 2003. 
Avritzer, Leonardo. Participatory institutions in democratic Brazil. Washington: Woodrow Wilson Center Press; Baltimore: The John Hopkins University Press, 2009. AVRITZER, Leonardo. Sociedade civil, instituições participativas e representação: da autorização à legitimidade da ação. Dados, v. 50, n. 3, p. 443-464, 2007a.

Avritzer, Leonardo (Org.). A participação social no Nordeste. Belo Horizonte: Editora UFMG, 2007b.

AvRITZER, Leonardo (Org.). A dinâmica da participação local no Brasil. São Paulo: Cortez, 2010.

AVRITZER, Leonardo. A qualidade da democracia e a questão da efetividade da participação: mapeando o debate. In: PIRES, Roberto Rocha C. (Org.). Efetividade das instituições participativas no Brasil: estratégias de avaliação. Brasília: Ipea, 2011. p. 13-29.

AVRITZER, Leonardo. Impasses da democracia no Brasil. Rio de Janeiro: José Olympio, 2016.

BRASIL. Ministério da Justiça. Secretaria da Cidadania e Departamento da Criança e do Adolescente. Estatuto da Criança e do Adolescente. Brasília, 1990.

BRASIL. Ministério da Justiça. Secretaria de Direitos Humanos. Lei no 8.242, de 12 de outubro de 1991. Cria o Conselho Nacional dos Direitos da Criança e do Adolescente (Conanda) e dá outras providências. Brasília, 1991.

BRASIL. Secretaria de Direitos Humanos. Decreto no 1.196, de 14 de julho de 1994. Dispõe sobre a gestão e administração do Fundo Nacional para a Criança e o Adolescente (FNCA), e dá outras providências. Brasília, 1994.

BRASIL. Presidência da República. Secretaria Especial de Direitos Humanos. Lei no 12.010, de 03 de agosto de 2009. Brasília, 2009.

BRASIL. Lei no 12.594, de 18 de janeiro de 2012. Institui o Sistema Nacional de Atendimento Socioeducativo (Sinase). Diário Oficial da União, Brasília, 18 de jan. 2012.

CôRTEZ, Soraya Vargas. As diferentes instituições participativas existentes nos municípios brasileiros. In: PIRES, Roberto Rocha C. (Org.). Efetividade das instituições participativas no Brasil: estratégias de avaliação. Brasília: Ipea, 2011. p. 137-150.

CUNHA, Eleonora Schettini Martins. A capacidade de deliberação dos Conselhos Municipais de Assistência Sócia e de Direitos da Criança e do Adolescente de Belo Horizonte. Pensar BH/Política Social, ano VIII, n. 24, p. 29-32, nov. 2009a.

CUNHA, Eleonora Schettini Martins. Efetividade deliberativa: estudo comparado de conselhos municipais de assistência social (1997/2006). Belo Horizonte: UFMG, 2009b. 376 f., enc. Tese (doutorado) - Universidade Federal de Minas Gerais, Faculdade de Filosofia e Ciências Humanas, Belo Horizonte.

CUNHA, Eleonora Schettini Martins. Inclusão social e política: o desafio deliberativo dos conselhos municipais de assistência social. In: AVRITZER, Leonardo (Org.). A dinâmica da participação local no Brasil. São Paulo: Cortez, 2010. p. 93-129.

CunHA, Eleonora Schettini M.; ThEOdoro, Hildelano Delanusse (Eds.). Desenho institucional, democracia e participação: conexões teóricas e possibilidades analíticas. Belo Horizonte: Editora D’Plácido, 2015. 
FARIA, Claudia Feres. Sobre os determinantes das políticas participativas: a estrutura normativa e o desenho institucional dos conselhos municipais da saúde e de direitos da criança e do adolescente. In: AVRITZER, L. (Org.). A participação social no Nordeste. Belo Horizonte: UFMG, 2007.

FARIA, Claúdia Feres; Coelho, Uriella Ribeiro. Entre o legal e o real: o que dizem as variáveis institucionais sobre os conselhos municipais de políticas públicas?. In: Avritzer, Leonardo (Org.). A dinâmica da participação local no Brasil. São Paulo: Cortez, 2010. p. 57-92.

FARIA, Claudia Feres; COELHO, Uriella Ribeiro. Desenho institucional: variáveis relevantes e seus efeitos sobre o processo participativo". In: PIRES, Roberto Rocha C. (Org.). Efetividade das instituições participativas no Brasil: estratégias de avaliação. Brasília: Ipea, 2011. p. 125-136.

FrotA, Maria Guiomar da Cunha. Associativismo civil e participação social: desafios de âmbito local e global na implementação dos direitos da criança. Rio de Janeiro: luperj, 2004. Tese (doutorado) - Instituto Universitário de Pesquisas do Rio de Janeiro, Rio de Janeiro.

FUKS, Mario; PERISSINOTTO, Renato. Recursos, decisão e poder: conselhos gestores de políticas públicas de Curitiba. Revista Brasileira de Ciências Sociais, v. 21, n. 60, p. 67-81, 2006.

HABERMAS, Jürgen. Direito e demcracia:entre facticidade e validade. V. II. Rio de Janeiro: Tempo Brasileiro, 2003. Cap. VII e VIII.

Lavalle, Adrián Gurza; Houtzager, Peter P.; CASTello, Graziela. Representação política e organizações civis: novas instâncias de mediação e os desafios da legitimidade. RBCS, v. 21, n. 60, p. 43-66, fev. 2006a.

Lavalle, Adrián Gurza; Houtzager, Peter P.; CAstello, Graziela. Democracia, pluralização da representação e sociedade civil. Lua Nova, n. 67 [cited 2007-10-18], p. 49-103, 2006b.

LAVALLE, Adrián Gurza; ARAúso, Cícero. O debate sobre a representação política no Brasil: nota introdutória. CADERNO $C R H$, Salvador, v. 21, n. 52, p. 9-12, jan./abr. 2008.

LAVALLE, Adrián Gurza. Aproximando agendas e agentes: apropriação, operação e ciclo de vidas dos conselhos gestores de políticas. In: ENCONTRO INTERNACIONAL Participação, Democracia e Políticas PúblicA, 2., maio 2015, Campinas. Anais... Campinas: Unicamp, 2015.

LAVALle, Adrian Gurza; VoIGT, Jessica; SerafiM, Lizandra. O que fazem os conselhos e quando o fazem? Padrões decisórios e o debate dos efeitos das instituições participativas. Dados, Rio de Janeiro, v. 59, n. 3, p. 609-650, set. 2016.

LÜCHMANN, Lígia Helena Hahn. A representação no interior das experiências de participação. Lua Nova, n. 70, p. 139-170, 2007.

MACPHERSON, Crawford Brough. A democracia liberal: origens e evolução. Rio de Janeiro: Zahar, 1978. p. 97-116.

MendonçA, Ricardo Fabrino. Mitigating systemic dangers: the role of connectivity inducers in a deliberative system. Critical Policy Studies, v. 10, p. 1-20, 2016. 
MENicuccl, Telma Maria Gonçalves. A política para crianças e adolescentes em capitais brasileiras: os conselhos de direitos importam? In: Avritzer, Leonardo. A dinâmica da participação local no Brasil. São Paulo: Cortez, 2010.

instituto Brasileiro de Geografia e Estatística (IBGE). MUNIC/IBGE. Perfil dos Municípios Brasileiros. Pesquisa de Informações Básicas Municipais. Rio de Janeiro: IBGE, 2009.

PARKINSON, John. Deliberating in the real world: problems of legitimacy in deliberative democracy. New York: Oxford, 2006.

Pateman, Carole. Participação e teoria democrática. Rio de Janeiro: Paz e Terra, 1992. p. 9-63.

PIRES, Roberto Rocha C; TOMAS, Maria Carolina. Instituições participativas e gestão municipal no Nordeste: uma análise dos efeitos da participação sobre as práticas de governo. In: AVRITZER, Leonardo (Org.). A participação social no Nordeste. Belo Horizonte: Editora UFMG, 2007. p. 163-193.

PIRES, Roberto Rocha C.; VAZ, Alexander Cambraia N. Participação faz diferença? Uma avaliação das características e efeitos da institucionalização da participação nos municípios brasileiros. In: AVRITZER, Leonardo (Org.). A dinâmica da participação local no Brasil. São Paulo: Cortez, 2010.

PIRES, Roberto RC; VAZ, A. C. Para além da participação: interfaces socioestatais no governo federal. Lua Nova, v. 93, p. 61-91, 2014.

PogReBINSCHI, Thamy et al. Relatório final de pesquisa. Entre representação e participação: as conferências nacionais e o experimentalismo democrático brasileiro. Rio de Janeiro: Secretaria de Assuntos Legislativos; luperj, 2010.

PRZEWORSKI, Adam; STOKES, Susan C.; MANIN, Bernard. Introduction. In: PrZEWORSKI, Adam; STOKES, Susan C.; MANIN, Bernard. Democracy, accountability, and representation. Cambridge: Cambridge Univ. Press, 1999.

SANTOS JúnIOR, Orlando Alves dos; AzEVEDo, Sérgio de; RIBEIRO, Luiz César de Queiroz. Democracia e gestão local: a experiência dos conselhos municipais no Brasil. In: SANTOS JúNIOR, Orlando Alves dos; RIBEIRo, Luiz César de Queiroz; AzeVedo, Sérgio de. Governança democrática e poder local: a experiência dos conselhos municipais no Brasil. Rio de Janeiro: Renavan, Fase, 2004. p. 11-56.

SILVA, Eduardo Moreira da. Deliberação e representação política nos conselhos setoriais. In: CONGRESSO LATINOAMERICANO DA ALACIP, 5., julho 2010, Buenos Aires. Anais... Buenos Aires: Alacip, 2010.

SILVA, Eduardo Moreira da; CunHA, Eleonora Schettini M. (Orgs.). Experiências internacionais de participação. São Paulo: Cortez, 2010.

SILVA, Eduardo Moreira da; RIBEIRO, Antonio Carlos Andrade. Sistemas deliberativos em perspectiva meso: a abordagem dos subsistemas aplicada aos conselhos de políticas públicas em Belo Horizonte. Opinião Pública, Campinas, v. 22, n. 1, p. 167194, 2016.

SILVA, E. M. et al. Deliberative systems in meso perspective: the subsystem of policy councils in the state of Minas Gerais. Anais eletrônicos/2016 ECPR Joint Sessions of Workshops. Pisa, 24 a 28 de abril de 2016. 
TATAGIBA, Luciana. Os conselhos gestores e a democratização das políticas públicas no Brasil. In: DAGNino, Evelina. (Org.). Sociedade civil e espaços públicos no Brasil. São Paulo: Paz e Terra, 2002. p. 47-103.

VAZ, Alexander Cambraia N. Da participação à qualidade da deliberação em fóruns públicos: o itinerário da literatura sobre conselhos no Brasil. In: PIRES, Roberto Rocha C. (Org.). Efetividade das instituições participativas no Brasil: estratégias de avaliação. Brasília: Ipea, 2011. p. 137-150.

WAMPLER, Brian. Activating democracy in Brazil: popular participation, social justice, and interlocking institutions. Notre Dame: University of Notre Dame Press, 2015.

YounG, Iris Marion. Representation and social perspective. In: Young, Iris Marion. Inclusion and democracy. e-book. New York: Oxford University Press, 2000.

\section{Eduardo Moreira da Silva}

Possui doutorado em Ciência Política pela Universidade Federal de Minas Gerais (UFMG). Atualmente é Professor Adjunto do Departamento de Ciência Política da UFMG. Contato: eduardovirtual2014@gmail.com 